\title{
Inhibition of miRNA-21 attenuates the proliferation and metastasis of human osteosarcoma by upregulating PTEN
}

\author{
CHEN LI, BINWU XU, XINXIN MIU, ZHONGBO DENG, HANG LIAO and LIANG HAO \\ Department of Orthopedic Surgery, The Second Affiliated Hospital of Nanchang University, \\ Nanchang, Jiangxi 330006, P.R. China
}

Received November 14, 2016; Accepted June 29, 2017

DOI: $10.3892 /$ etm.2017.5477

\begin{abstract}
The present study aimed to investigate the expression of micro (mi)RNA-21 in osteosarcoma cells, and its role in inhibiting the invasion and metastasis of osteosarcoma. Human osteosarcoma MG-63 cells and osteoblast hFOB1.19 cells were used to compare the expression of miRNA-21 using reverse transcription-quantitative polymerase chain reaction analysis. A miRNA-21 mimic or inhibitor were transfected into the MG-63 cells to upregulate and downregulate the expression of miRNA-21, respectively. The present study investigated the proliferation and invasion of transfected MG-63 cells using MTT and Transwell assays. Western blot analyses were used to investigate the regulation of important proteins in the phosphatase and tensin homolog/phosphoinositide 3-kinase/RAC- $\alpha$ serine/threonine-protein kinase (PTEN/PI3K/AKT) signaling pathway. Compared with hFOB1.19 cells, miRNA-21 expression was significantly upregulated in the MG-63 cells $(\mathrm{P}<0.01)$, which lead to increased proliferation. Downregulating miRNA-21 expression reduced the proliferation of MG-63 cells compared with hFOB1.19 cells. Invasion assays and western blot analyses revealed that the overexpression of miRNA-21 significantly enhanced the invasion ability of MG-63 cells and the expression of phosphorylated (p-)AKT, while downregulation of miRNA-21 expression reduced the protein level of AKT and p-AKT. In the MG-63 cells, miRNA-21 upregulation significantly inhibited the protein level of PTEN, resulting in significantly increased AKT and PI3K protein levels $(\mathrm{P}<0.01)$. In conclusion, the results of the present study indicate that the expression of miRNA-21, $\mathrm{PI} 3 \mathrm{~K}$ and AKT is increased in the osteosarcoma cell line MG-63, which results in reduced expression of PTEN and
\end{abstract}

Correspondence to: Professor Liang Hao, Department of Orthopedic Surgery, The Second Affiliated Hospital of Nanchang University, 1 Minde Road, Nanchang, Jiangxi 330006, P.R. China E-mail: haollhao96@126.com

Key words: microRNA-21, phosphatase and tensin homolog, osteosarcoma, phosphoinositide 3-kinase/RAC- $\alpha$ serine/threonineprotein kinase signaling pathway increased expression of proteins in the PI3K/AKT signaling pathway, and thus increases the aggressiveness of osteosarcoma cells.

\section{Introduction}

Osteosarcoma is one of the most common malignant tumors of the bone, and is typically located in the distal femur and proximal tibia. The malignancy of osteosarcoma is high, with an extremely poor patient prognosis. Osteosarcoma often results in pulmonary metastasis within a number of months, with a 3-5 year survival rate of 5-20\% (1). Surgery remains the primary treatment option for patients with osteosarcoma; however, the incidence of relapse for these patients is high (1). For patients with advanced stage osteosarcoma who have missed the opportunity for surgical therapy, comprehensive treatments, including radiotherapy, chemotherapy and biological agents, have become the main option for therapy $(2,3)$. Therefore, it is important to improve understating of the mechanisms underlying the occurrence, progression, invasion and metastasis of osteosarcoma to provide better treatments for this disease.

Phosphatase and tensin homolog (PTEN) is a tumor suppressor gene that is located on chromosome 10q23.3. The transcription product of the gene is a $515 \mathrm{~kb}$ long mRNA (4). PTEN belongs to the protein tyrosine phosphatase gene family and is the first tumor suppressor with bispecific phosphatase activity identified thus far. PTEN is associated with the occurrence of several types of tumor, and serves an important role in tumor cell growth, apoptosis, adhesion, migration and invasion (5). Previous studies have revealed that the downregulation or deletion of PTEN activates the phosphoinositide 3-kinase/RAC- $\alpha$ serine/threonine-protein kinase (PI3K/AKT) signaling pathway, resulting in the occurrence, development, invasion and metastasis of cancer $(6,7)$.

MicroRNAs (miRNAs/miRs) are small RNA molecules that are 17-25 nucleotides long and serve an important role in the regulation of gene expression $(8,9)$. Although the number of miRNAs in the human genome is less than that of protein-coding genes, they are thought to regulate the expression of more than half of human mRNAs (10). However, few studies have reported the role of miRNAs in osteosarcoma and their mechanism of action. miRNA-21 was revealed to be abnormally expressed in a variety of tumor cells and is one 
of the few miRNAs that is expressed in all solid malignant tumors $(10,11)$. A number of genes, including PTEN and tissue inhibitor of metalloproteinase-3, have been identified as targets of miRNA-21 $(11,12)$.

To better understand the role and mechanism of action of miRNA-21 in the invasion and metastasis of osteosarcoma, in addition to cell apoptosis and proliferation, the expression of miRNA-21 was investigated. This revealed that miRNA-21 expression was upregulated in osteosarcoma cells. In addition, the impact of miRNA-21 on the expression of PTEN was investigated. The findings from the present study provide insights into the role of miRNA-21 in osteosarcoma, and reveal potential therapeutic targets for the prevention and treatment of this disease.

\section{Materials and methods}

Cell lines and culture. The human osteosarcoma cell line, MG-63, and osteoblast cell line, hFOB1.19, were purchased from the cell bank of the Typical Culture Preservation Committee of the Chinese Academy of Sciences (Beijing, China). Cells were cultured in Dulbecco's modified Eagle's medium (DMEM) supplemented with $10 \%$ fetal bovine serum (FBS; Gibco; Thermo Fisher Scientific, Inc., Waltham, MA, USA) at $37^{\circ} \mathrm{C}$ with $5 \% \mathrm{CO}_{2}$. Cell proliferation and viability were assayed using an MTT cell proliferation assay kit according to the manufacturer's protocol (cat. no. C0009; Beyotime Institute of Biotechnology, Haimen, China).

Reverse transcription-quantitative polymerase chain reaction $(R T-q P C R)$ analysis. Total RNA was extracted from the cells using TRIzol reagent according to the manufacturer's protocol (Invitrogen; Thermo Fisher Scientific, Inc.), and measured for quantity and purity using the NanoDrop ${ }^{\text {TM }} 2000$ (Applied Biosystems; Thermo Fisher Scientific, Inc.). Reverse transcription of the RNA was performed using the High-Capacity RNA-to-cDNA ${ }^{\mathrm{TM}}$ kit (Thermo Fisher Scientific, Inc.), according to the manufacturer's protocol. qPCR analysis was performed using the TaqMan Gene Expression Master mix (Thermo Fisher Scientific, Inc.) in a total volume of $20 \mu \mathrm{l}$ containing $5 \mu \mathrm{l}$ cDNA products, $10 \mu \mathrm{l}$ TaqMan ${ }^{\circledR}$ Gene Expression Master Mix (2X), $100 \mu \mathrm{M}$ primers and $4 \mu \mathrm{l}$ nuclease-free water. The primer sequences for miRNA-21 were: Forward, 5'-TGTACCACCTTGTCG GATAG-3' and reverse, 5'-CTGCTGTTGCCATGAGAT-3'. GAPDH was used as internal reference gene with the following primers: Forward, 5'-GCGCGTCGTGAAGCG TTC-3' and reverse, primer 5'-GTGCAGGGTCCGAGG GT-3'.

The thermocycling conditions were as follows: $50^{\circ} \mathrm{C}$ for $2 \mathrm{~min}, 95^{\circ} \mathrm{C}$ for $10 \mathrm{~min}, 37$ cycles of $95^{\circ} \mathrm{C}$ for $15 \mathrm{sec}$ and $1 \mathrm{~min}$ at $60^{\circ} \mathrm{C}$. Samples were run in triplicate and the mean value was calculated for each case. The data were managed using RQ Manager software (version 1.2.1; Applied Biosystems; Thermo Fisher Scientific, Inc.). Relative mRNA expression was calculated using $2^{-\Delta \Delta \mathrm{Cq}}$ method as previously described (13).

Transfections. The transfection of MG-63 cells was performed using Lipofectamine ${ }^{\circledR} 2000$ (Thermo Fisher Scientific, Inc.) according to the manufacturer's protocol. Briefly, MG-63 cells were seeded at a concentration of $1 \times 10^{5}$ cells/well in 6-well culture plates. Following $24 \mathrm{~h}$ of culturing (70\% confluence), the cells were transfected with $50 \mathrm{nM}$ hsa-miR-21 mimic (cat. no. 4464066) or inhibitor (cat. no. 4464084; both Thermo Fisher Scientific, Inc.). The transfection efficiency was checked by $\mathrm{qPCR}$ and visualization of positive controls by confocal microscopy (Olympus FV-1000 Inverted Microscope; Olympus Corporation, Tokyo, Japan).

Cell invasion assays. For the assessment of invasion, $5 \times 10^{5}$ transfected cells in serum-free DMEM were placed into the upper chamber of a Transwell insert coated with Matrigel (BD Biosciences, Franklin Lakes, NJ, USA). For the two experiments, media containing $10 \%$ FBS were added to the lower chamber. Following $24 \mathrm{~h}$ of incubation at $37^{\circ} \mathrm{C}$, the cells remaining on the upper membrane were removed with cotton wool, whereas the cells that had migrated or invaded through the membrane were stained with $2 \%$ crystal violet in $25 \%$ methanol/PBS at room temperature for $15 \mathrm{~min}$, then imaged and counted using an EVOS XL Core inverted microscope (Thermo Fisher Scientific, Inc.). The experiments were independently repeated three times.

Western blot analysis. MG-63 cells were transfected with miRNA-21 mimic or inhibitor for $48 \mathrm{~h}$. Subsequently, proteins were extracted using the ReadyPrep ${ }^{\mathrm{TM}}$ Protein Extraction kit (Total Protein) (Bio-Rad Laboratories, Inc., Hercules, CA, USA) and quantified using the BCA Protein Quantification kit (Vazyme, Piscataway, NJ, USA), according to the manufacturer's protocol. A total of $10 \mu \mathrm{g}$ per lane of protein was separated by $12 \%$ SDS-PAGE and transferred to PVDF membranes (EMD Millipore, Billerica, MA, USA). The membranes were blocked with 5\% defatted milk (OriGene Technologies, Inc., Beijing, China) at room temperature for $1 \mathrm{~h}$ before reacting to the secondary antibody. Human AKT/phosphorylated (p-)AKT, PTEN and PI3K protein expression levels were quantified using rabbit polyclonal antibodies specific for each protein $(1: 1,000$; Signalway Antibody and Santa Cruz Biotechnology). The expression levels of these three proteins were standardized to GAPDH using a mouse polyclonal antibody directed against GAPDH (ABS16; 1:1,000; EMD Millipore) at room temperature for $2 \mathrm{~h}$. The primary antibodies were detected using goat anti-rabbit horseradish peroxidase-conjugated secondary antibodies (cat. no. A0208; 1:200; OriGene Technologies, Inc.) at room temperature for $1 \mathrm{~h}$. Immunoreactive bands were visualized using Western Lighting Chemiluminescence Reagent Plus (PerkinElmer, Inc., Waltham, MA, USA), according to the manufacturer's protocol and then quantified by densitometry (Image J Pro Plus v1.51; National Institutes of Health, Bethesda, MD, USA) using a ChemiGenius Gel Bio Imaging system (Syngene, Frederick, MD, USA).

Statistical analyses. Statistical analyses were performed using GraphPad Prism software (version 6.0; GraphPad Software, Inc., La Jolla, CA, USA). All experiments were repeated at least three times and performed in triplicate. Data are expressed as the mean \pm standard deviation, and means were compared using the Student's t-test. $\mathrm{P}<0.05$ was considered to indicate a statistically significant difference. 


\section{Results}

miRNA-21 is upregulated in MG-63 osteosarcoma cells. qPCR assays revealed that miRNA-21 expression was significantly upregulated in MG-63 cells compared with hFOB1.19 cells $(\mathrm{P}<0.01$; Fig. 1$)$.

miRNA-21 increases the proliferation and invasion of MG-63 osteosarcoma cells. To investigate the effect of miRNA-21 on the proliferation and invasion of MG-63 cells, a miRNA-21 mimic or inhibitor were transfected into the MG-63 cells to upregulate and downregulate miRNA-21 expression, respectively. qPCR analyses demonstrated that the mRNA expression level of miRNA-21 was significantly increased or decreased following the transfection with the mimic or inhibitor, respectively, compared with the control group $(\mathrm{P}<0.05$, Fig. 2A).

MTT assays demonstrated that at 48 and $72 \mathrm{~h}$ following miRNA-21 mimic or inhibitor transfection, the proliferation of MG-63 cells was significantly increased in cells transfected with the mimic and decreased in cells transfected with the inhibitor compared with their respective control groups ( $\mathrm{P}<0.05$, Fig. 2B).

The Transwell assays (Fig. 2C) revealed that following transfection with the miRNA-21 mimic, MG-63 cell invasion was increased significantly compared with the control group $(85.2 \pm 10.6$ vs. $47.6 \pm 2.6)$, while transfection with the miRNA-21 inhibitor resulted in a significantly reduced invasion ability compared with the control $(32.8 \pm 12.7$ vs. $58.4 \pm 4.9)$ (both $\mathrm{P}<0.05$; data not shown).

miRNA-21 increases PTEN/PI3K/AKT signaling. The above results indicated that the expression level of miRNA-21 impacts the proliferation and invasion of the osteosarcoma cells. Considering this, the influence of miRNA-21 on the expression of proteins in the PTEN/PI3K/AKT signaling pathway was analyzed. The activation state of the PI3K/AKT signaling pathway was determined by measuring the protein expression level of p-AKT. The results demonstrated that the protein expression of p-AKT was positively associated with the miRNA-21 level. Upregulation of miRNA-21 expression significantly increased the p-AKT level compared with treatment with the miRNA-21 inhibitor $(\mathrm{P}<0.01$; Fig. 3$)$. In regards to other important proteins in the PI3K/AKT signaling pathway, the miRNA-21 mimic significantly inhibited the expression of PTEN and increased the expression of PI3K compared with cells treated the miRNA-21 mimic $(\mathrm{P}<0.01$; Fig. 3).

\section{Discussion}

Non-coding RNA has been demonstrated to serve important roles in numerous biological processes, and the development and treatment of diseases (14). As a group of non-coding RNAs, miRNAs exist in a wide variety of organisms and have been demonstrated to have important biological functions with complicated mechanisms of action, each having single or multiple target genes to regulate (14-16). miRNA-21 is a ubiquitous miRNA, which is expressed at abnormal levels in numerous types of cancer, including colorectal cancer, bile

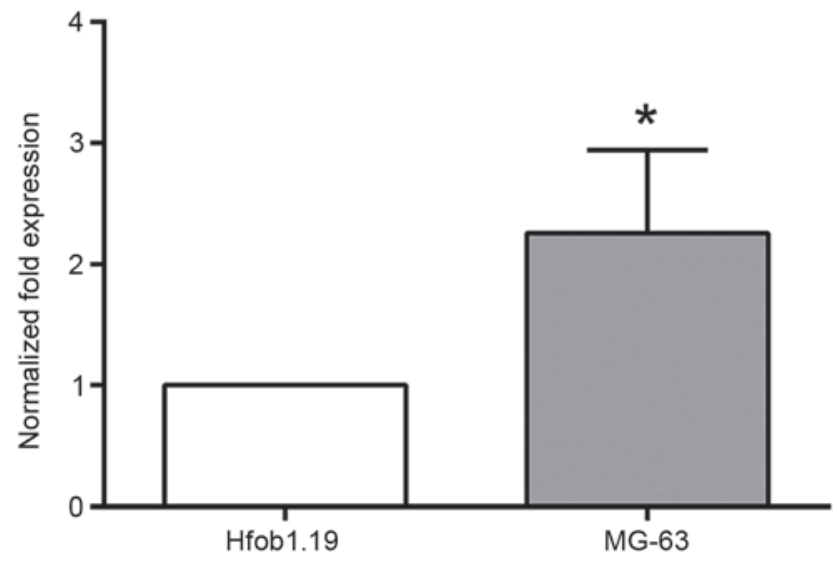

Figure 1. microRNA-21 is overexpressed in osteosarcoma cells. " $\mathrm{P}<0.01$ vs. hFOB1.19 cells.

duct carcinoma, lymphoma, multiple myeloma and glioma, suggesting that it is an oncogene (15-17).

At present, the pathogenesis of osteosarcoma remains unclear. As with other solid tumors, the activation of oncogenes and the abnormal expression of tumor suppressor genes are considered the main reasons for the occurrence of osteosarcoma (18). Previous studies have revealed that PTEN inhibits the proliferation, invasion and metastasis of tumor cells (19-21). The mutation and deletion of the PTEN gene have been confirmed to occur in osteosarcoma in dogs, where, in $60 \%$ of osteosarcoma cells, PTEN gene expression was suppressed or the gene was deleted (22). It has previously been demonstrated that in human osteosarcoma AKT, which is known to promote cell proliferation, invasion and angiogenesis, is highly expressed and activated (23). One of the causes of abnormal expression and activation of AKT is the abnormal expression of its upstream regulatory gene, PTEN (24).

The present study demonstrated that, compared with the normal osteoblast cell line hFOB1.19, PTEN in MG-63 osteosarcoma cells was significantly downregulated, while the levels of the downstream proteins AKT and p-AKT were significantly elevated. This indicates that in human osteosarcoma cells PTEN is abnormally expressed, which is consistent with the results of the aforementioned studies.

Using a bioinformatics method, it has been predicted that PTEN is the target gene of miRNA-21 and a number of studies have demonstrated that miRNA-21 can regulate the mRNA expression of PTEN $(12,24)$. However, little is known about the expression of miRNA-21 in osteosarcoma. Analyses in the present study revealed that the expression of miRNA-21 in osteosarcoma cells was upregulated in comparison with normal cells. The impact of miRNA-21 on cell behavior and the PTEN/PI3K/AKT pathway in MG-63 osteosarcoma cells was then investigated using a miRNA-21 mimic and inhibitor. The results of the present study demonstrated that the downregulation of miRNA-21 in MG-63 cells resulted in decreased proliferation, and invasion. By contrast, the upregulation of miRNA-21 in MG-63 cells using a mimic led to increased cell proliferation and invasion ability, suggesting that miRNA-21 promotes the growth and development of osteosarcoma. 
A

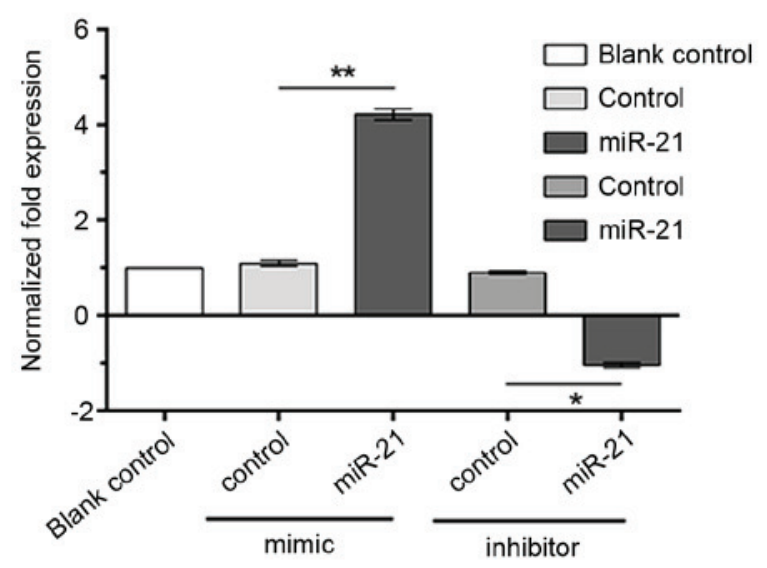

B

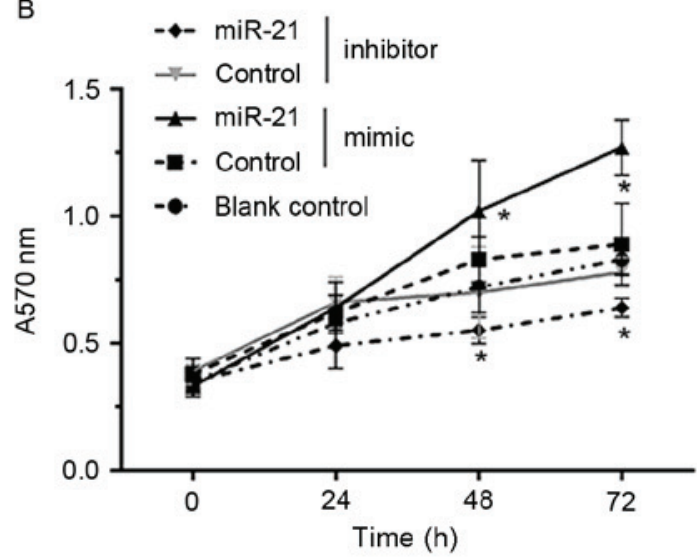

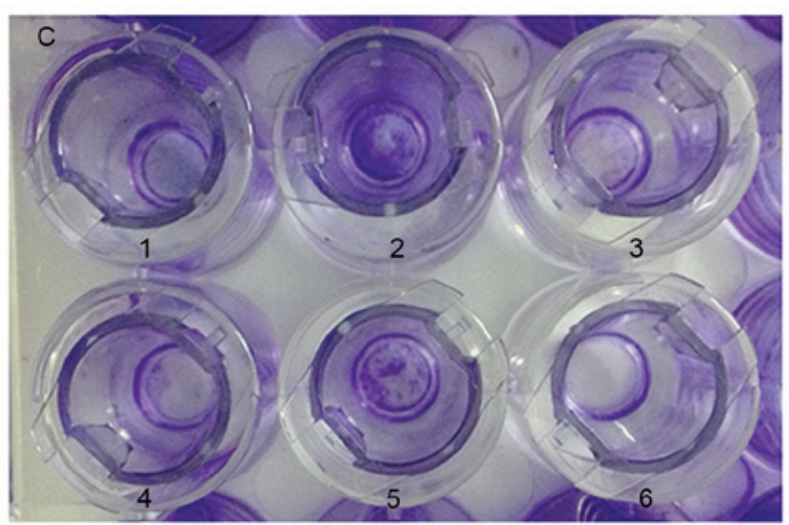

Figure 2. miR-21 overexpression increases the aggressiveness of osteosarcoma. (A) Relative miR-21 level, (B) proliferation and (C) invasion ability of MG-63 cells following transfection with the miR-21 mimic or inhibitor. Wells 1 and 4, blank control; well 2, the miR-21 mimic; well 3, the mimic control; well 5, the inhibitor control; well 6 , the miR21 inhibitor. ${ }^{*} \mathrm{P}<0.05,{ }^{* *} \mathrm{P}<0.01$ vs. the control group. miRNA/miR, microRNA.
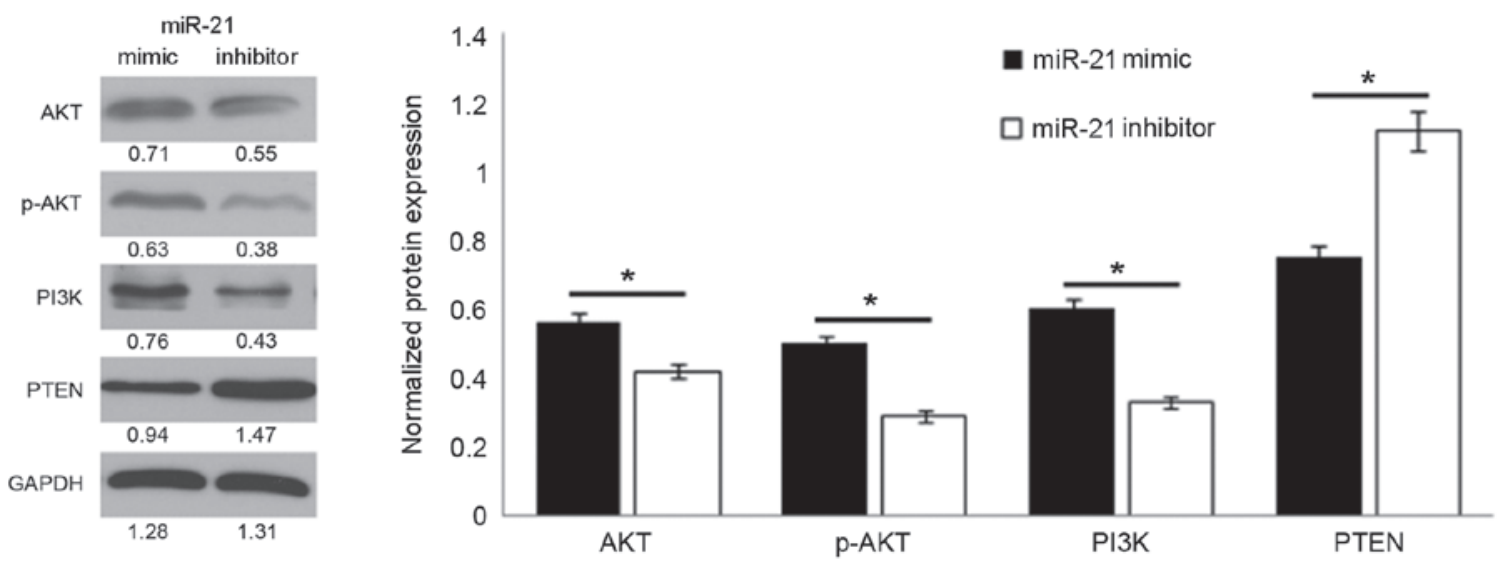

Figure 3. miR-21 overexpression activates the PTEN/PI3K/AKT signaling pathway. Western blot and quantification of the expression levels of proteins in the PTEN/PI3K/AKT signaling pathway. " $\mathrm{P}<0.01$. miR, microRNA. AKT, RAC- $\alpha$ serine/threonine-protein kinase; p-, phosphorylated; PI3K, phosphoinositide 3-kinase; PTEN, phosphatase and tensin homolog.

Furthermore, analysis of the expression of proteins in the PTEN/PI3K/AKT signaling pathway demonstrated that miRNA-21 inhibited the expression of PTEN to regulate the activity of the PTEN/PI3K/AKT signaling pathway. The level of miRNA-21 was positively associated with the level of AKT/p-AKT, indicating that miRNA-21 regulates the proliferation and invasion of MG-63 cells. Similarly, Meng et al $(25,26)$ revealed that miRNA-21 regulated PTEN expression in bile duct cancer and hepatocellular cancer, and promoted the invasion of tumor cells. Therefore, the results of the present study indicate that in osteosarcoma cells the abnormal expression of miRNA-21 may activate the PTEN/PI3K/AKT signaling pathway by regulating the expression of PTEN. This suggests that miRNA-21 functions as an oncogene. The results of the present study may provide potential therapeutic targets for the prevention and treatment of this disease. 


\section{References}

1. Berner K, Johannesen TB, Berner A, Haugland HK, Bjerkehagen B, Bøhler PJ and Bruland ØS: Time-trends on incidence and survival in a nationwide and unselected cohort of patients with skeletal osteosarcoma. Acta Oncol 54: 25-33, 2015.

2. Ziyan W and Yang L: MicroRNA-21 regulates the sensitivity to cisplatin in a human osteosarcoma cell line. Ir J Med Sci 185: 85-91, 2016.

3. Venkatramani R, Murray J, Helman L, Meyer W, Hicks MJ, Krance R, Lau C, Jo E and Chintagumpala M: Risk-Based therapy for localized osteosarcoma. Pediatr Blood Cancer 63: 412-417, 2016.

4. Nakanishi A, Kitagishi Y, Ogura Y and Matsuda S: The tumor suppressor PTEN interacts with p53 in hereditary cancer (Review). Int J Oncol 44: 1813-1819, 2014.

5. Rizvi MM, Alam MS, Mehdi SJ, Ali A and Batra S: Allelic loss of 10q23.3, the PTEN gene locus in cervical carcinoma from Northern Indian population. Pathol Oncol Res 18: 309-313, 2012

6. Wu YR, Qi HJ, Deng DF, Luo YY and Yang SL: MicroRNA-21 promotes cell proliferation, migration, and resistance to apoptosis through PTEN/PI3K/AKT signaling pathway in esophageal cancer. Tumour Biol 37: 12061-12070, 2016.

7. Xue R, Lei S, Xia ZY, Wu Y, Meng Q, Zhan L, Su W, Liu H, Xu J, Liu Z, et al: Selective inhibition of PTEN preserves ischaemic post-conditioning cardioprotection in STZ-induced Type 1 diabetic rats: Role of the PI3K/Akt and JAK2/STAT3 pathways. Clin Sci (Lond) 130: 377-392, 2016.

8. Lim LP, Lau NC, Garrett-Engele P, Grimson A, Schelter JM, Castle J, Bartel DP, Linsley PS and Johnson JM: Microarray analysis shows that some microRNAs downregulate large numbers of target mRNAs. Nature 433: 769-773, 2005.

9. Zhu L, Liu J and Cheng G: Role of miRNAs in schistosomes and schistosomiasis. Front Cell Infect Microbiol 4: 165, 2014.

10. Lee RC, Feinbaum RL and Ambros V: The C. Elegans heterochronic gene lin-4 encodes small RNAs with antisense complementarity to lin-14. Cell 75: 843-854, 1993.

11. Lu X, Fan Q, Xu L, Li L, Yue Y, Xu Y, Su Y, Zhang D and Wang L: Ursolic acid attenuates diabetic mesangial cell injury through the up-regulation of autophagy via miRNA-21/PTEN/Akt/mTOR suppression. PLoS One 10: e0117400, 2015.

12. Liu X, Luo F, Ling M, Lu L, Shi L, Lu X, Xu H, Chen C, Yang Q, Xue J, et al: MicroRNA-21 activation of ERK signaling via PTEN is involved in arsenite-induced autophagy in human hepatic L-02 cells. Toxicol Lett 252: 1-10, 2016.

13. Livak KJ and Schmittgen TD: Analysis of relative gene expression data using real-time quantitative PCR and the 2(-Delta Delta $\mathrm{C}(\mathrm{T}))$ method. Methods 25: 402-408, 2001.
14. Feng Y, Fan Y, Huiqing C, Zicai L and Quan D: The emerging landscape of long non-coding RNAs. Yi Chuan 36: 456-468, 2014 (In Chinese).

15. Wagner A, Mayr C, Bach D, Illig R, Plaetzer K, Berr F, Pichler M, Neureiter D and Kiesslich T: MicroRNAs associated with the efficacy of photodynamic therapy in biliary tract cancer cell lines. Int J Mol Sci 15: 20134-20157, 2014.

16. Liu L, Chen L, Xu Y, Li R and Du X: microRNA-195 promotes apoptosis and suppresses tumorigenicity of human colorectal cancer cells. Biochem Biophys Res Commun 400: 236-240, 2010.

17. Griffiths-Jones S, Grocock RJ, van Dongen S, Bateman A and Enright AJ: miRBase: microRNA sequences, targets and gene nomenclature. Nucleic Acids Res 34 (Database Issue): D140-D44, 2006.

18. Anderson ME: Update on survival in osteosarcoma. Orthop Clin North Am 47: 283-292, 2016.

19. Gildea JJ, Herlevsen M, Harding MA, Gulding KM, Moskaluk CA, Frierson HF and Theodorescu D: PTEN can inhibit in vitro organotypic and in vivo orthotopic invasion of human bladder cancer cells even in the absence of its lipid phosphatase activity. Oncogene 23: 6788-6797, 2004.

20. Chu EC and Tarnawski AS: PTEN regulatory functions in tumor suppression and cell biology. Med Sci Monit 10: RA235-RA241, 2004.

21. Maehama T, Okahara F and Kanaho Y: The tumour suppressor PTEN: Involvement of a tumour suppressor candidate protein in PTEN turnover. Biochem Soc Trans 32: 343-347, 2004.

22. Levine RA, Forest T and Smith C: Tumor suppressor PTEN is mutated in canine osteosarcoma cell lines and tumors. Vet Pathol 39: 372-378, 2002.

23. Wu ZH, Tao ZH, Zhang J, Li T, Ni C, Xie J, Zhang JF and Hu XC: MiRNA-21 induces epithelial to mesenchymal transition and gemcitabine resistance via the PTEN/AKT pathway in breast cancer. Tumour Biol 37: 7245-7254, 2016.

24. Sarkar S, Dubaybo H, Ali S, Goncalves P, Kollepara SL, Sethi S, Philip PA and Li Y: Down-regulation of miR-221 inhibits proliferation of pancreatic cancer cells through up-regulation of PTEN, p27(kip1), p57(kip2), and PUMA. Am J Cancer Res 3: 465-477, 2013.

25. Meng F, Henson R, Lang M, Wehbe H, Maheshwari S, Mendell JT, Schmittgen TD and Patel T: Involvement of human micro-RNA in growth and response to chemotherapy in human cholangiocarcinoma cell lines. Gastroenterology 130: 2113-2129, 2006.

26. Meng F, Henson R, Wehbe-Janek H, Ghoshal K, Jacob ST and Patel T: MicroRNA-21 regulates expression of the PTEN tumor suppressor gene in human hepatocellular cancer. Gastroenterology 133: 647-658, 2007. 